\title{
“Eu não quero ficar no lugar das mulheres peladas, não!": As causas das internações de mulheres no Hospital Psiquiátrico Adauto Botelho (Goiânia, Goiás)
}

\author{
"I don't want to stay in the naked women's place, no!": The causes of \\ hospitalizations of women at the Psychiatric Hospital Adauto Botelho (Goiânia, \\ Goiás)
}

Railda Aparecida Barbosa Barreto; Tiago Cassoli

Universidade Federal de Goiás

\section{RESUMO:}

O presente artigo discute as formas de encaminhamento de mulheres ao Hospital Psiquiátrico Adauto Botelho (Goiânia - GO). A pesquisa foi realizada a partir de oito prontuários psiquiátricos, produzidos entre as décadas de 1970 e 1990, e a análise ocorreu mediante a perspectiva histórico-genealógica de Michel Foucault. São os fragmentos de histórias que emergiram nesses documentos que tecem a escrita deste trabalho. E, por meio deles, evidenciamos que o Hospital Psiquiátrico Adauto Botelho funcionou como um espaço de confinamento, silenciamento e moralização de mulheres que apresentavam comportamentos incompatíveis com os padrões socialmente impostos na época - elas não eram boas filhas, esposas, mães e donas de casa. Dado o valor atribuído à conduta moral das mulheres na construção de seus diagnósticos psiquiátricos, conclui-se que mais do que uma instituição de tratamento, o hospital psiquiátrico era um instrumento de normalização e controle da sociedade goiana.

Palavras-chave: loucura; mulheres; Hospital Psiquiátrico Adauto Botelho (GO).

\section{ABSTRACT:}

This article discusses the ways of referring women to the Psychiatric Hospital Adauto Botelho (Goiânia - GO). The research was carried out based on eight psychiatric records, produced between the 1970s and 1990s, and the analysis occurred through the historical-genealogical perspective of Michel Foucault. It is the fragments of stories that emerged in these documents that weave the writing of this work. And, through them, we show that the Adauto Botelho Psychiatric Hospital functioned as a space of confinement, silencing and moralization of women who presented behavior incompatible with the socially imposed standards at the time They were not good daughters, wives, mothers and housewives . Given the value attributed to the moral conduct of women in the construction of their psychiatric diagnoses, it is concluded that more than a treatment institution, the psychiatric hospital was an instrument of normalization and control of society in Goiás.

Key-words: madness; women; Psychiatric Hospital Adauto Botelho (GO).

DOI: 10.12957/mnemosine.2020.57662 
“Eu não quero ficar no lugar das mulheres peladas, não!”: As causas das internações de mulheres no Hospital Psiquiátrico Adauto Botelho (Goiânia, Goiás). 213

\section{Introdução}

No ano de 1954 foi inaugurado em Goiás, especificamente na capital Goiânia, o Hospital Psiquiátrico Adauto Botelho. O hospital psiquiátrico fez parte de um amplo projeto do Serviço Nacional de Doenças Mentais (SNDM) que, sob a direção do psiquiatra Adauto Junqueira Botelho, possibilitou grandes transformações na assistência aos doentes mentais e na expansão de hospitais psiquiátricos pelo Brasil, conforme ressalta Piccinini (2009).

Segundo Paula (2011), o Hospital Psiquiátrico Adauto Botelho representou a edificação de um projeto moderno, respondendo aos anseios do então médico e governador Pedro Ludovico Teixeira, que viu nesta construção a possibilidade de concretizar seus ideais de modernidade e progresso, almejados desde a transferência da capital de Goiás para Goiânia.

A mudança da capital possibilitou não somente a ruptura com as velhas oligarquias de poder, mas o nascimento de um novo tempo, marcado pela emergência de uma nova sociedade que não estivesse mais presa ao passado e que representasse o moderno e o saudável (PAULA, 2011). Este foi o solo propício para o desenvolvimento do saber médico psiquiátrico que, aliado ao discurso político, auxiliaria na consolidação dos objetivos do governo de Goiás, como se analisa no discurso proferido pelo Secretário de Saúde, Dr. José Peixoto da Silveira, durante a solenidade de inauguração do hospital psiquiátrico.

Dentre os deveres primordiais do Governo, nenhum pode sobrepor-se ao de assistir à saúde do povo; este problema no nosso vasto Brasil encerra tamanha gravidade, tal amplidão e magnitude, que para ele se deve atentar com grande patriotismo; os recursos e os esforços máximos do Governo precisam ser mobilizados para curar, robustecer e valorizar o homem brasileiro. Sintetiza-se nestas palavras, o zelo de um homem pela vida de nossa gente, e definem-se os propósitos do Governo de promover o aperfeiçoamento da nossa raça.

[...] Inicialmente, cumpre salientar o espírito patriótico do Sr. Diretor do Serviço Nacional de Doenças Mentais, Professor Adauto Botelho, que, espontaneamente, ofereceu, a este Estado, longínquo, a oportunidade de vir a possuir uma unidade hospitalar, que quando completada, rivalizar-se-á com as mais modernas do País. Este o motivo, sobremaneira justo, por que foi escolhido o vosso nome, Sr. Prof. Adauto Botelho, para esta casa, num justo preito de reconhecimento ao seu benfeitor, seja apenas uma modesta homenagem ao vosso ilustre e aureolado nome (Folha de Goyaz 03/04/1954).

A criação do hospital psiquiátrico surgiu como marco institucional da assistência psiquiátrica em Goiás. Desta feita, representou uma transformação com as antigas práticas de atendimento aos doentes mentais e "possibilitou a institucionalidade da classificação dos indivíduos e da delimitação de fronteiras entre comportamentos normais e anormais" (PAULA, 2011: 74).

Cumpre assinalar que antes da institucionalização da psiquiatria em Goiás, não havia instituição específica para a assistência dos doentes mentais. Na maioria das vezes, os que se 
tornavam incômodos e representavam uma ameaça à ordem estabelecida e à paz social, eram encaminhados para as cadeias públicas. Outra forma de controle social era a internação no Hospital São Pedro de Alcântara, na Santa Casa de Misericórdia ou no Asilo São Vicente de Paulo, etc. (PAULA, 2011; SOUZA, 2010). Este último procedimento, visto como um serviço de humanidade e de caridade ao próximo, também evidenciava práticas de confinamento e exclusão social.

Como símbolo de progresso e grande avanço para a psiquiatria em Goiás, a construção do Hospital Psiquiátrico Adauto Botelho representou a edificação de uma "obra humanitária tão necessária e utilitariamente agradável ao Governo do Estado" (Folha de Goyaz, 04 abr. 1954). No entanto, os objetivos humanitários de assistência aos doentes mentais evidenciavam os interesses da medicalização social, onde a psiquiatria, aliada ao governo, cumpriria a tarefa de intervir em tudo aquilo que fosse considerado desviante.

Para Birman (1978), ao estabelecer o campo de variação do comportamento humano, a psiquiatria se apresentava enquanto normatizadora e recuperadora das individualidades que se desviaram no exercício das normas estabelecidas. Nesse ponto, o hospital psiquiátrico tornarse-ia o lugar privilegiado para a normatização de corpos indisciplináveis e para o desenvolvimento e legitimação das práticas e discursos.

Para atender as exigências das modernas correntes psicodinâmicas, o serviço de Higiene Mental tão sobranceiramente por vós impulsionado é por demais justificado e coaduna-se perfeitamente com o presente e o futuro da psiquiatria. Hoje mesmo tivestes oportunidade de encarecer o valor desta medida profilática, ao afirmar que o aumento das psicopatias acompanha o avanço da civilização. Esta assertiva aparentemente paradoxal esta coerente com o que observamos. (Discurso pronunciado pelo Secretário de Saúde, Dr. José Peixoto da Silveira, na inauguração do Hospital Psiquiátrico Adauto Botelho. Folha de Goyaz, 04 abr. 1954).

Por ser o único hospital público do gênero no Estado, durante seus quarenta e um anos de funcionamento, o Hospital Psiquiátrico Adauto Botelho tornou-se referência em Goiás, sendo a ele encaminhados homens e mulheres que a ciência psiquiátrica e a sociedade julgavam ser passíveis de reclusão e tratamento. Entretanto, considerando que os encaminhamentos não partiam exclusivamente da perspectiva médica, mas de outros setores da sociedade - tais como a polícia e a família, etc. -, tamanha procura fez com que a sobrecarga viesse a se instalar desde os primeiros anos de funcionamento.

Pode-se dizer que não somente a sobrecarga, mas as péssimas condições de vida dos pacientes, alimentação deficiente, precariedade das instalações, uso de práticas violentas, entre 
“Eu não quero ficar no lugar das mulheres peladas, não!”: As causas das internações de mulheres no Hospital Psiquiátrico Adauto Botelho (Goiânia, Goiás). 215

outros problemas, passaram a assolar a instituição. A respeito desses acontecimentos, destacamos os excertos abaixo:

Proibidas as visitas no Hospital Psiquiátrico Adauto Botelho. Motivos: falta de roupa para os enfermos, falta de medicação, doentes dormem no chão, falta de assistência por parte da Secretaria de Saúde. (Proibidas as visitas no Hospital Psiquiátrico Adauto Botelho, Folha de Goyaz, 14 dez. 1958).

Sobre nota do Diário Oficial, a respeito do estado deplorável em que se acha o Hospital Psiquiátrico Adauto Botelho, conforme declaração da presidente da Associação Beneficente da Vila Nova, a reportagem foi procurada ontem por uma senhora que esteve naquele nosocômio, sentindo a miséria e a arbitrariedade que ali ocorrem; onde os internos passam privações de toda natureza, principalmente da alimentação, higiene e leito; além da maneira péssima com que são tratados. Adiantou ainda que uma enfermeira do hospital garantiu haver dezenas de tuberculosos no nosocômio. (Tuberculosos no Adauto Botelho, Folha de Goyaz, 21 fev. 1961).

Em virtude dos avanços da Reforma Psiquiátrica que percorria o Brasil desde o final da década de 1970, o Hospital Psiquiátrico Adauto Botelho foi desativado em 1995 e demolido em 1997. Na época do fechamento, os duzentos e oito pacientes asilares que ainda permaneciam no local foram transferidos para unidades de assistência psiquiátrica no Estado. Segundo uma matéria publicada no jornal O popular (1995), os pacientes, muito dos quais estavam no Adauto Botelho desde a sua inauguração em 1954, foram espalhados por clínicas psiquiátricas particulares e instituições, tanto na capital quanto no interior de Goiás.

Diferente de Minas Gerais, onde foi construído o Museu da Loucura ${ }^{1}$ com o objetivo de preservar partes da história do Hospital Colônia de Barbacena, em Goiás não houve interesse por parte do poder público em transformar o Hospital Psiquiátrico Adauto Botelho em patrimônio histórico e cultural. Tal façanha do governo, segundo Paula (2011), poderia significar o silenciamento e o esquecimento da exclusão do louco em Goiás, onde, reduzido aos escombros, nada mais representaria.

$\mathrm{Na}$ época da demolição, muitos dos prontuários psiquiátricos que ainda estavam dentro do hospital psiquiátrico foram destruídos. Os que resistiram foram levados para o arquivo de um pronto socorro psiquiátrico da cidade, ficando sob a responsabilidade da Secretaria Municipal de Saúde de Goiânia (GO). No entanto, pela falta de organização e precariedade do arquivo, o material encontra-se incompleto, sujo e muito danificado.

Este artigo, que é fruto de uma pesquisa aprovada pelos comitês de ética da Secretaria Municipal de Saúde (Goiânia - GO) e da Universidade Federal de Goiás, se propõe a discutir as formas de encaminhamento de mulheres ao Hospital Psiquiátrico Adauto Botelho. O interesse por essa temática justifica-se pelo incômodo que surgiu durante uma pesquisa 
realizada no mestrado, cujo intuito era o de analisar, a partir de prontuários psiquiátricos, como a família se apresentava nos discursos e nas práticas da psiquiatria em Goiás. No decorrer da pesquisa, notamos que a maioria dos prontuários encontrados era referente às internações de mulheres.

No entanto, é importante explicar que não pretendemos assinalar que as mulheres representavam a maioria dos internos no Hospital Psiquiátrico Adauto Botelho. Para isso seria necessário uma pesquisa que contemplasse todos os registros de entrada no hospital psiquiátrico, o que foge dos objetivos do nosso estudo. Sabendo que uma pesquisa histórica nunca é totalizante, aqui discutimos sobre o que se fez evidente no contato que tivemos com as fontes documentais, com os fragmentos de histórias de mulheres consideradas loucas que foram retiradas do convívio social e internadas no hospital psiquiátrico.

Dessa forma, utilizando as fontes documentais enquanto intercessores, buscamos investigar, nos fragmentos das histórias de mulheres que foram atravessadas pelo saber médico psiquiátrico, as causas das internações e quais os elementos discursivos se juntaram na construção de seus diagnósticos psiquiátricos.

Para o alcance dos objetivos propostos, foram analisados oito prontuários psiquiátricos, produzidos entre as décadas de 1970 e 1990. A escolha do período se deu por duas razões: primeiro, pela ausência de prontuários que datavam do período inicial de funcionamento do hospital psiquiátrico, isto é, das décadas de 1950 e 1960; segundo, por se tratar de uma pesquisa genealógica, que não se prendeu à linearidade, à continuidade ou à totalização da história, mas às rupturas e à fluidez dos discursos e práticas que se produziram no interior do hospital psiquiátrico.

Cumpre ressaltar que partimos do entendimento de que os prontuários psiquiátricos fazem parte do procedimento de exame, que, segundo Foucault (1987), diz respeito a uma técnica de individualização e normalização; um mecanismo disciplinar em que se articulam as relações de poder com a formação de saberes. Por meio do exame, produz-se um campo documentário minucioso; um sistema intenso de registro sobre os indivíduos, colocando-os sob a vigilância e controle de um saber permanente e de técnicas disciplinares.

Sendo assim, os prontuários psiquiátricos evidenciam os discursos de poder e de verdade; ao mesmo tempo, discursos toscos e grosseiros que foram "formulados exclusivamente por pessoas qualificadas, no interior de uma instituição científica" (FOUCAULT, 2010: 7). 
“Eu não quero ficar no lugar das mulheres peladas, não!”: As causas das internações de mulheres no Hospital Psiquiátrico Adauto Botelho (Goiânia, Goiás). 217

É importante destacar que as problematizações levantadas a partir dos prontuários psiquiátricos não se esgotam neste texto; do contrário, elas abrem espaço para o surgimento de novos questionamentos. Sendo assim, esperamos que outros pesquisadores possam se interessar e escrever sobre os vestígios de vidas que ainda sobrevivem e insistem em erguer suas vozes e contar suas histórias por meio dos documentos.

\section{A chegada das mulheres ${ }^{2}$ ao Hospital Psiquiátrico Adauto Botelho}

Múltiplos caminhos foram percorridos pelas mulheres que chegaram ao Hospital Psiquiátrico Adauto Botelho. Podemos dizer que antes mesmo de serem levadas ao hospital psiquiátrico e diagnosticadas pela psiquiatria, cada uma já carregava o peso de interpretações construídas a partir do entendimento que a sociedade e a família diziam possuir acerca da loucura/doença mental.

Aqui, atenta-se para o processo que faz com que uma pessoa se torne um doente mental, ou melhor, o que Goffman (1987) denomina construção da carreira moral do doente mental. Nas palavras do autor, esta carreira se apresenta em três fases principais: o período anterior à entrada no hospital, o período de internamento e o período posterior à alta no hospital. Em todas as fases, progressivas mudanças alteram a maneira como a pessoa se relaciona consigo mesma e com os outros.

Segundo Carrion (2011), quando buscamos saber sobre o caminho percorrido em direção ao hospital psiquiátrico, devemos também considerar o processo que transforma alguém em um doente mental, cujos fragmentos de vida emergem nos prontuários. No entanto, conforme discute a autora, devemos ter a convicção de que, ao olharmos para as histórias, é impossível calcular o peso que os diagnósticos e as hospitalizações tiveram na vida de cada pessoa.

Goffman (1987) ressalta que é relativamente pequeno o número de pessoas que procuram o hospital psiquiátrico voluntariamente, quer pelo entendimento de que esta decisão será boa para elas, ou por um acordo estabelecido com a própria família. Para o autor, o que se analisa nesse processo é que a maioria das pessoas chega contra a vontade: "alguns se internam porque a família pediu que o fizesse, ou ameaçou que, em caso contrário, romperiam os laços de família; chegam obrigados, com vigilância policial; chegam enganados pelos outros” (p. 116). Sobre caminhos percorridos e chegadas, contamos histórias assim.

A história de Zélia é intrigante, principalmente pela maneira como ela chegou ao Hospital Psiquiátrico Adauto Botelho. Pelas rasuras no prontuário, não foi possível saber o ano 
exato e a causa de sua primeira internação, tampouco o número de vezes que esteve internada no hospital psiquiátrico. Contudo, o que chamou a atenção foi uma anotação referente à readmissão no ano de 1990, quando Zélia “chegou sozinha, de ‘mala e cuia’ e um rádio em uma sacola, dizendo que queria internar" (Prontuário nº 761).

É curioso notar o sentido dado à frase "mala e cuia", visto que podemos pensar que a expressão foi considerada pertinente para evidenciar a situação da mulher que simplesmente juntou tudo o que possuía e partiu rumo ao hospital psiquiátrico. Podemos dizer que a linguagem utilizada buscou expressar exatamente a situação de uma mulher que chegou ao hospital carregando consigo a roupa do corpo e os poucos pertences.

Zélia, que era natural de Goiânia - GO, dizia ser rejeitada pela família e, por essa razão, além de seus pertences, levou um bilhete que foi escrito por uma vizinha. O bilhete tinha por objetivo reforçar o pedido pela internação no hospital psiquiátrico.

Por favor, Doutor, interna essa criatura. Ela está desorientada. É que a casa dela foi toda queimada. Acabou tudo, ela está bebendo muito e só fica na rua sofrendo. A família não cuida dela. Então, deixa ela aí alguns dias, por favor. Sou vizinha dela, mas não posso fazer nada por ela. (Prontuário $\mathrm{n}^{\circ} 761$ ).

Descrita pela psiquiatria como "desorientada e fora de si” (Prontuário $\mathrm{n}^{\circ}$ 761), não soubemos o que houve após a sua internação. No entanto, cabem alguns questionamentos, uma vez que, longe de ser apenas um local de passagem, o hospital psiquiátrico tenha funcionado como moradia, ou melhor, como um campo de depósito para Zélia e todos aqueles que não se tornavam parte integrante da sociedade e da família. Um lugar de confinamento para os indivíduos não aceitos pela sociedade considerada normal.

De acordo com Goffman (1987), frequentemente, por trás da chegada ao hospital psiquiátrico existe alguma pessoa, um denunciante, que pratica a ação que finalmente culmina com a internação psiquiátrica. $\mathrm{O}$ autor ainda esclarece que mesmo que o denunciante não seja a pessoa que toma a primeira providência, é ele que inicia o caminho do paciente para o hospital psiquiátrico. Dessa feita, passamos então a analisar as internações involuntárias, realizadas pela polícia e pelas famílias das pacientes.

Transgressão, loucura e violência acompanharam a chegada de Helena, internada pela polícia no ano de 1978. A sua história conta sobre o poder repressivo da polícia e a sua íntima relação com a psiquiatria. Polícia que silenciava algum ato na rua e que também era responsável pelas internações no hospital psiquiátrico, conforme expõe Carrion (2011). 
“Eu não quero ficar no lugar das mulheres peladas, não!”: As causas das internações de mulheres no Hospital Psiquiátrico Adauto Botelho (Goiânia, Goiás). 219

Helena que era solteira e chegou ao Hospital Psiquiátrico Adauto Botelho com vinte e dois anos de idade, apresentava grave distúrbio de conduta, conforme afirmava o psiquiatra.

A paciente veio conduzida pela polícia. Estava pirada na rua e a polícia trouxe para o hospital psiquiátrico. Apresenta grave distúrbio de conduta e agressividade; possui hematomas no rosto e no pescoço. Higiene péssima. Diz ser só e não ter ninguém no mundo (Prontuário n ${ }^{\circ}$ 839).

Poucos detalhes. O prontuário não apresenta informações que possam esclarecer sobre quem era Helena, o porquê das marcas em seu corpo, por quanto tempo ficou internada, entre outras questões que, infelizmente, os documentos analisados não puderam responder. Porém, o que se fez evidente em sua história foi o uso do discurso pueril, associado ao discurso do medo, para descrever a maneira como a paciente foi encontrada e o risco apresentado para a população, caso não fosse internada.

Estar pirada na rua possibilitou que Helena estivesse sob os olhos atentos de uma polícia que internava, de um poder que tinha por função silenciar quem incomodava muito e, em contrapartida, defender a sociedade do perigo que a sua loucura representava.

[...] é o discurso que não apenas se organiza em torno do campo da perversidade, mas igualmente em torno do problema do perigo social: isto é, ele também será o discurso do medo, um discurso que terá por função detectar o perigo e opor-se a ele. É, pois, um discurso do medo e um discurso da moralização, é um discurso infantil, é um discurso cuja organização epistemológica, toda ela comandada pelo medo e pela moralização, não pode deixar de ser ridícula, mesmo em relação à loucura. (FOUCAULT, 2010: 31).

Outros rostos que compuseram o Hospital Psiquiátrico Adauto Botelho também ajudam a responder sobre a chegada das mulheres. E eles, vivos e pulsantes, nos falam sobre a participação da família enquanto elemento denunciante nas internações. Prática frequente, os prontuários analisados apontam nitidamente para a relação entre a psiquiatria e a família, e o hospital psiquiátrico representando a solução necessária para as mulheres que apresentavam comportamentos que se desviavam da normalidade.

Chama atenção a história de uma japonesa que chamaremos de Naomi. Solteira e doméstica, Naomi foi internada pela primeira vez em 1963, aos vinte anos de idade. A seu respeito, apenas que era esquizofrênica e havia sido levada por uma tia. Contudo, alguns detalhes sobre uma avaliação psiquiátrica foram descritos em seu prontuário:

Diz estar doente da carne que foi mal feita. Todo o corpo vai mal. Tem muitos filhos, mas deve matá-los. Não quer sair do hospital. Reclama de dores na cabeça. É preciso insistir que ela responda em português, pois ela prefere responder em língua materna - japonês. Durante as observações constatou-se que toma atitudes e expressões corporais diversas: quando fala em japonês, ora se "torna" uma pessoa ativa, fala alto, parecendo dar ordens; ora se inclina e o tom de voz muda, representando uma anciã. (Prontuário nº 372). 
Nota-se a ênfase dada aos comportamentos de Naomi, principalmente o uso da língua materna para responder às perguntas do psiquiatra. Mesmo que não seja o foco de nossa análise, uma questão se faz necessária: a mudança repentina da linguagem também seria traço de sua loucura ou uma maneira de ainda preservar a sua singularidade dentro do hospital psiquiátrico? Talvez Naomi, ao agir assim, tentasse evidenciar a própria produção da loucura dentro de um hospital psiquiátrico, pois, como diz Moffat (1980), tudo o que o paciente faz dentro de um hospício pode ser considerado como parte do seu delírio; qualquer que seja a mensagem emitida, ela é reinterpretada como "coisa de louco".

Sem condições de mantê-la em casa, a família de Naomi considerou pertinente a sua internação. Repetidas e longas internações, inclusive. Para se ter uma ideia, na anotação a respeito da última vez que esteve no hospital psiquiátrico consta que a paciente, readmitida no dia 06 de abril de 1973, recebeu alta somente no dia 14 de novembro de 1990.

Os prontuários que falam de chegadas e partidas também nos contam sobre um lugar difícil de sair tão rapidamente como se chegou, de um caminho sem volta. Moffat (1980) sustenta que "o hospício é como um poço profundo no qual se entra rápido, mas do qual é difícil sair, pois suas paredes são escorregadias como na incompreensão e no abandono, e não há onde agarrar-se" (p. 16). Dessa feita, para o alívio de suas famílias, as mulheres também iam ao Hospital Psiquiátrico Adauto Botelho para nunca mais voltar.

Uma vez entregue ao hospício, o louco passava, quase sempre em caráter definitivo, para o "outro lado do espelho", deixando de ser um peso para a familia. As visitas, realizadas nos horários determinados, iam escasseando com o correr do tempo, até que, entregue ao seu destino inexorável, não mais se constituísse numa lembrança incômoda e perdesse completamente o seu espaço social, encontrando aquilo que Basaglia chama de "morte civil". (CUNHA, 1986: 118).

Na busca por documentos sobre o hospital psiquiátrico, encontramos fragmentos de duas histórias, contadas em um jornal. Apesar de não termos encontrado os prontuários psiquiátricos dessas pacientes, consideramos que falar sobre elas vai ao encontro dos objetivos desse artigo, uma vez que as histórias carregam as marcas das internações, do esquecimento e do abandono de mulheres no hospital psiquiátrico. Além do mais, elas mostram que nem sempre era o discurso técnico e científico que fomentava e determinava as internações.

Teresa chegou ao Hospital Psiquiátrico Adauto Botelho no ano de 1985, por encaminhamento de um hospital geral da cidade de Goiânia, onde esteve internada após ter sido vítima de um atropelamento. Natural da Bahia, Teresa foi trazida de sua terra por uma família 
que a havia contratado como empregada doméstica. Depois do acidente, Teresa, que não se lembrava de nada, nem sequer dos nomes de seus patrões, foi abandonada no hospital (O Popular, 29 out. 1995).

Tida como indigente, o hospital geral considerou pertinente encaminhá-la para o hospital psiquiátrico, onde permaneceu internada por dez anos, até ser transferida para uma unidade de assistência psiquiátrica. Sem o diagnóstico de doença mental, a entrada de Teresa no hospital psiquiátrico apontava para as práticas de encaminhamento tão comuns entre hospitais na época, além de legitimar a atuação social da psiquiatria, "em que os limites imprecisos da normalidade se transformavam em elementos do controle social" (COUTO, 1994: 58). Levada de um lugar a outro, o jornal nos conta que Teresa nunca mais soube notícias de sua família.

Já a história de Divina é contada após o fechamento do Hospital Psiquiátrico Adauto Botelho em 1995, quando, sem obter notícias sobre a sua família, ela foi transferida para uma clínica psiquiátrica em Goiânia.

Depois de uma longa busca por informações, a equipe da clínica descobriu que sua mãe e seus sete irmãos residiam em Goiânia e que, nos vinte e dois anos em que esteve internada, jamais buscaram saber a respeito da paciente. Inclusive, ao serem informados que Divina tinha condições de retornar ao convívio familiar, "eles recusaram recebê-la de volta, utilizaram da influência de políticos e a oferecer dinheiro para que ela continuasse internada" (O Popular, 02 mar. 1998).

A rejeição também se fez presente nas idas à clínica psiquiátrica para resolver o destino de Divina, já que em nenhum momento seus familiares quiseram vê-la. Para lidar com essa resistência e fazer com que a família assumisse a responsabilidade pela paciente, a direção da instituição acionou o Ministério Público - GO. Porém, a longa espera da justiça não permitiu que Divina voltasse para casa. No leito psiquiátrico, ela morreu em novembro de 1998.

Segundo Carrion (2011), mais do que um estabelecimento em que faz morada, mais do que seus muros, a instituição psiquiátrica atravessa o seu próprio espaço de confinamento e invade a cidade, toma os seus moradores mais indisciplinados, às vezes entregues de bom grado por suas famílias. Assim, um poder que extrapola os próprios muros institucionais e se introduz na sociedade, nas casas e nas famílias, evidencia o funcionamento do hospital psiquiátrico como veículo de moralização da família, conforme discute Cunha (1986).

Evidentemente, tais apontamentos se fizeram presentes em nossa análise, nos convidando, inclusive, a discutir as internações de mulheres como um efeito da aliança entre as 
famílias e a psiquiatria. Trazendo o que se tornou mais evidente nos prontuários, também podemos pensar na internação psiquiátrica enquanto meio de moralização de corpos femininos.

Aqui, lembremo-nos de Cunha (1986), ao discorrer sobre a construção da loucura de mulheres internadas no Hospício do Juquery, em São Paulo. Para a autora, as mulheres eram quase sempre internadas sob a alegação de distúrbios relativos, principalmente, à esfera privada - espaço que lhes coube na definição de papeis sexuais e sociais.

Na verdade, as regras do comportamento das mulheres estiveram, desde um amplo processo de elaboração de uma imagem feminina ideal, apenas relacionada à esfera corporal e familiar: boas mães, boas filhas, boas esposas. Se há um espaço social menor a ser ocupado, em função do estrito arcabouço de normas que lhes foram impostas, há, para as mulheres, menores ocasiões e oportunidades de transgressão. Neste sentido, a relação do distúrbio psíquico com a rigidez das regras de comportamento socialmente impostas é, na condição feminina, talvez mais evidente. (CUNHA, 1986:143).

Contrariando a imagem feminina ideal, continuemos a contar histórias de mulheres que ao desviarem dos padrões impostos, foram objetos de discursos normativos e internadas no hospital psiquiátrico. No entanto, dada a regularidade do que se apresentou nos documentos analisados, tratemos agora de filhas, esposas, mães e donas de casa que, ao fugirem do esperado socialmente, não mereciam o adjetivo de "boas".

\section{As filhas do Hospital Psiquiátrico Adauto Botelho}

No ano de 1977, Adélia, aos onze anos de idade, foi internada no Hospital Psiquiátrico Adauto Botelho. Por solicitação do Juizado de menores do Estado de Goiás, Adélia foi encaminhada ao hospital psiquiátrico sob a justificativa de perambular pelas ruas da cidade e incomodar a população. Segundo informações do Juizado, ela tinha pais vivos, porém vivia abandonada nas ruas.

No ano seguinte, Adélia foi novamente internada no hospital psiquiátrico. No entanto, o responsável por sua internação foi um vereador que informou se tratar de uma "menor infantil, inquieta e agressiva" (Prontuário $\mathrm{n}^{\circ}$ 1.104). Pela psiquiatria, Adélia, que se apresentava calma no momento da internação e com higiene regular, foi diagnosticada como uma "paciente com distúrbio de comportamento" (Prontuário n $\mathrm{n}^{\circ}$ 1.104).

Atenhamo-nos a outro prontuário, o de Rosa, cuja primeira internação também ocorreu no ano de 1977. Assim como Adélia, Rosa foi encaminhada ao hospital psiquiátrico pelo Juizado de menores do Estado de Goiás, no entanto, sob a alegação de ser uma "menor-órfã" e 
“Eu não quero ficar no lugar das mulheres peladas, não!”: As causas das internações de mulheres no Hospital Psiquiátrico Adauto Botelho (Goiânia, Goiás). 223

se encontrar em "estado de abandono e com sério problema de conduta (homossexualismo)" (Prontuário $n^{\circ}$ 1.382). Na época da internação, Rosa estava com treze anos de idade.

Para subsidiar o encaminhamento ao Hospital Psiquiátrico Adauto Botelho, no ato da internação, foi entregue um parecer realizado por uma assistente social do Juizado. O documento, que é rico em detalhes, apresenta uma história que teve início três anos antes de Rosa ser levada ao hospital psiquiátrico. E além de Rosa, outros personagens compuseram o enredo. Ressaltamos que todos os nomes citados foram alterados para garantir a privacidade dos envolvidos.

Em 27.05.74 compareceu o casal Dalva e Joaquim, acompanhado da menor em tela. Os responsáveis pela menor relataram que esta é abandonada e tem apresentado problemas de conduta e evasão domiciliar. Foi encaminhada à APAE (segue relatório psicológico, anexo, feito nessa data): Aos 15.07.74 comparece a responsável pela menor para entregá-la para este juízo, alegando ser, a mesma, malcriada, desobediente e vadia. Colocou que uma senhora por nome Alice pretendia responsabilizar-se pela menor. Ficou de voltar ao juizado, acompanhada pela menor, pela referida D. Alice e pelo irmão da menor em pauta. No dia 16.07.74, compareceu D. Dalva, responsável pela menor. Essa informou-nos que a menor evadiu-se do seu lar. (Parecer do Juizado de Menores de Goiás, 1977, Prontuário no 1.382).

Abandono, problemas de conduta, evasão domiciliar, malcriação, desobediência e vadiagem, foram os termos usados para traçar o perfil de Rosa só no primeiro parágrafo do documento. Se no prontuário de Adélia havia poucas informações a respeito de sua situação antes de ingressar no hospital psiquiátrico, o de Rosa impressiona quanto à descrição dos acontecimentos que antecederam a sua chegada ao hospital psiquiátrico.

Pode-se dizer que a intenção era o de mostrar que o hospital psiquiátrico era a única solução para um caso que havia esgotado todas as outras possibilidades de controle, conforme se analisa a seguir.

Em 30.08.74, a menor foi encaminhada ao Comissariado pelo Sr. Sebastião, o qual comunicou ter a menor aparecido em sua casa solicitando acomodação. A menor foi encaminhada aos responsáveis. Aos 20.11.74, D. Dalva entregou a menor para o Juizado, alegando não ter condições de tê-la em sua companhia. Foi encaminhada para a Casa de Plantão. Em 05.05.75, a menor evadiu-se da Casa de Plantão. Em 20.10.75, a mesma foi encaminhada ao Centro de Recepção e Triagem (C.R.T.). Aos 20.02.76, a menor foi apreendida por vadiagem pelo Comissariado de Menores. No dia 17.04.76, a menor foi encaminhada ao Plantão do Comissariado por estar problemas de saúde. O Comissariado a encaminhou à OSEGO, onde foi medicada. Em 20/04/1976 foi encaminhada ao Sanatório Eurípedes Barsanulfo. Aos 11.08.76 foi encaminhada à Casa de Plantão, pois havia recebido alta no referido Sanatório. Dia 20.09.76 a menor evadiu-se da Casa de Plantão. Em 19.01.77 a menor foi encaminhada a este Juízo pelo Juizado de São Paulo - SP. (Parecer do Juizado de Menores de Goiás, 1977, Prontuário $\mathrm{n}^{\circ} 1.382$ ). 
Rosa não era apenas a "menor-órfã", mas uma adolescente com sérios problemas de conduta, que necessitava de disciplina psiquiátrica. Fruto de uma "família desestruturada", conforme o seu prontuário, o que se sabe sobre seus pais biológicos é somente que sua mãe falecera no ano de 1970, ficando a menor sob a responsabilidade dos seus padrinhos - Dalva e Joaquim. No entanto, em razão das dificuldades financeiras do casal e a da conduta de Rosa, ela também havia morado com outras famílias.

Meses após a internação de Rosa, Dalva e Joaquim solicitaram a sua alta hospitalar. No entanto, ano seguinte, a adolescente foi novamente internada no hospital psiquiátrico. Nesse momento, além de apresentar "grave comprometimento de conduta", Rosa também apresentava "síndrome oligofrênica e déficit intelectivo" (Prontuário $\mathrm{n}^{\mathrm{o}}$ 1.382). A partir de então, semelhante ao prontuário de Adélia, não houve nenhum registro sobre a sua saída do hospital psiquiátrico.

Pelos fragmentos encontrados nos prontuários, Adélia e Rosa ficaram sob o alvo de medidas disciplinares que buscavam tratar os problemas apresentados. Tratava-se de duas adolescentes que deveriam ser internadas no hospital psiquiátrico, mesmo que, inicialmente, não apresentassem nenhuma perturbação mental que justificasse tal procedimento. Assim, considerando o peso dado aos valores morais na elaboração dos diagnósticos psiquiátricos, podemos pensar que a loucura de ambas também era moral.

No entanto, a internação de Rosa pôs em questão o próprio funcionamento do hospital psiquiátrico, na medida em que um dos psiquiatras questionou tal prática. Ele, que dizia ser Rosa uma “paciente sem queixas clínicas” (Prontuário n 1.382), questionava uma prática muito comum no Hospital Psiquiátrico Adauto Botelho:

Não vejo necessidade de manter a paciente internada. Solicito providências neste sentido do Serviço Social. Pergunto: Até quando o Pronto Socorro Psiquiátrico e o Adauto vão servir de abrigo para os menores que criam problemas nas ruas? (Prontuário $\mathrm{n}^{\circ} 1.382$ ).

O encaminhamento de Adélia e Rosa ao hospital psiquiátrico foi visto como o caminho mais adequado, já que seus comportamentos eram incompatíveis com o esperado socialmente para uma adolescente. Assim, ao ultrapassar os limites do tolerável, a internação psiquiátrica se constituiu como a solução necessária de controle social, pois, ao psiquiatrizar aquilo que era estranho, ofereceria "uma alternativa política e moralmente aceitável para famílias atingidas pela desgraça e pela vergonha, para governos embaraçados pela necessidade de dispor de saídas institucionais de exclusão e controle" (CUNHA, 1986: 160). 
“Eu não quero ficar no lugar das mulheres peladas, não!”: As causas das internações de mulheres no Hospital Psiquiátrico Adauto Botelho (Goiânia, Goiás). 225

\section{As esposas, mães e donas de casa do Hospital Psiquiátrico Adauto Botelho}

Outras vozes se fizeram evidentes em nossa pesquisa, agora nos convidando para discutir sobre as mulheres que foram internadas pelos maridos. Atingidas pela loucura e encerradas no hospital psiquiátrico, elas nos contam sobre internações que foram justificadas pelo rompimento a um modelo feminino idealizado e normalizado. Modelo que, de acordo com Maluf e Mott (2006), se baseava na figura feminina de boa mãe, boa esposa e boa dona de casa.

Segundo Cunha (1989), a quebra desse modelo, apresentada como recusa ou resistência às próprias leis da natureza e às inclinações naturais do espírito feminino, se tornava o ponto de engate para que a psiquiatria estrategicamente se apresentasse como reforço da família e usufruísse de sua cumplicidade. Sendo assim, conforme Couto (1994), o hospital psiquiátrico não era apenas um espaço que se pretendia curativo para os portadores de desequilíbrios emocionais, mas se apresentava como um micro-universo das relações sociais, sendo capaz de excluir ou tentar normalizar as pessoas que haviam rompido os parâmetros sociais.

Erigidas em instância jurídica e aproveitando-se das prerrogativas de um tribunal a quem caberia julgar as condutas, a psiquiatria e a família pediam e obtinham com facilidade a internação de mulheres consideradas desviantes, conforme nos diz Cunha (1989). Ainda de acordo com a autora, a internação de mulheres evidenciava a maior propensão das famílias em livrar-se de seus fracassos afetivos do que em abrir mão do responsável pela sua manutenção financeira. Desse modo,

Há pouca hesitação para a internação de mulheres, decidida por seus maridos, pais, irmãos à menor "suspeita" ou desconforto causado por seu comportamento; os homens, ao contrário, em geral precisavam tornar-se muito incômodos, "reincidir", adquirir uma visibilidade incontestável em sua loucura antes que as famílias decidissem enviá-los ao hospício. (CUNHA, 1989: 129).

O Hospital Psiquiátrico Adauto Botelho era um desses locais em que os maridos internavam as mulheres que desviaram do destino traçado socialmente - elas não eram boas esposas, mães e donas de casa. Podemos dizer que a aliança entre a família e a psiquiatria era tão evidente, que ambas se tornavam complementares.

À primeira cabia buscar em seu interior as mulheres que apresentavam desvios das normas, encaminhá-las ao hospital psiquiátrico e prestar as informações julgadas como necessárias; já à psiquiatria, sustentada por discursos ditos científicos, caberia diagnosticar, tratar e devolvê-las recuperadas para as suas famílias. Em outras palavras, a psiquiatria traria de volta a ordem que havia sido rompida anteriormente (FOUCAULT, 2006). 
É nesse sentido que podemos olhar para a internação de Luzia. Não foi possível precisar o ano exato de sua primeira internação, já que as anotações encontradas referiam-se ao ano de 1986, quando ela foi readmitida no hospital psiquiátrico. Na época, Luzia estava com trinta anos de idade.

O responsável pela sua internação foi o marido e a queixa principal que possibilitou a construção do diagnóstico psiquiátrico foi a de que Luzia apresentava "grave alteração de conduta" (Prontuário $\mathrm{n}^{\mathrm{o}}$ 1.723). Segundo o relato do marido, as manifestações que surgiram após o casamento influenciavam diretamente no cumprimento das tarefas de uma mãe e dona de casa, pois Luzia, "recusa tomar a medicação prescrita. Não dorme e não deixa ninguém dormir, chamando pela mãe. Sem condições de cuidar dos afazeres diários. As crianças estão largadas" (Prontuário n ${ }^{\circ}$ 1.723).

Dias após a internação, Luzia foi novamente submetida a uma avaliação psiquiátrica. Conforme a anotação, a paciente "apática, prostrada ao leito e delirante" (Prontuário no 1.723) manifestava o seu descontentamento com a situação vivenciada. Descontentamento reinterpretado como traço de seu quadro delirante.

Na minha casa não tem televisão, nem geladeira e o meu marido quando chega em casa, só sabe brigar comigo. A minha tristeza é saber que o meu marido tem outra mulher e que na casa dela tem tudo isso. Daí me dá uma tristeza e vontade de fazer coisas erradas. (Prontuário $\left.\mathrm{n}^{\mathrm{o}} 1.723\right)$.

A história de Carmen também apresenta elementos que possibilitam reforçar que o hospital psiquiátrico era o espaço adequado para que alguns maridos internassem as mulheres cuja loucura também se manifestava na inadequação às tarefas de cuidadora da família e da própria casa. Por solicitação do marido, ela foi internada no ano de 1979, sob o diagnóstico de "Indiferença". Assim, de acordo com a observação psiquiátrica:

Apresentou-se ao exame com vestes e cabelos em desalinho. Chorando e soluçando, não respondeu as perguntas. Segundo informações do marido, há mais ou menos vinte dias, a paciente começou a apresentar distúrbio de conduta e isolar do ambiente, abandonando o cuidado com os filhos e a casa. Sai pelas ruas ou pelo mato, não conversa e não dorme (Prontuário $\mathrm{n}^{\mathrm{o}} 1.457$ ).

Durante o período em que esteve internada no Hospital Psiquiátrico Adauto Botelho, por várias vezes, Carmen se mostrou preocupada com a família: "no momento paciente com bom contato conosco, mas na enfermaria chora de preocupação com os filhos"; "Na enfermaria a paciente fica chorando e falando na família o tempo todo. Está preocupada com os filhos" (Prontuário $\mathrm{n}^{\circ}$ 1.457). 
“Eu não quero ficar no lugar das mulheres peladas, não!”: As causas das internações de mulheres no Hospital Psiquiátrico Adauto Botelho (Goiânia, Goiás). 227

Reduzida e silenciada por seus diagnósticos, Joana, aos trinta e dois anos de idade, também foi encaminhada ao hospital psiquiátrico por apresentar comportamentos incompatíveis com o ambiente familiar e doméstico. Pelas características apresentadas, podemos dizer que ela também fazia parte da categoria de mulheres que se furtaram a seu papel natural de mãe-e-esposa, segundo nos conta Cunha (1989). Os registros encontrados no seu prontuário psiquiátrico evidenciam os discursos e as práticas que se produziram e sustentaram a aliança entre a família e a psiquiatria.

Joana foi internada no ano de 1979 por solicitação do marido. Conforme as anotações, pelo fato de se encontrar dormindo no momento da internação, a construção do seu diagnóstico se deu a partir do relato do marido e de um ofício emitido pelo delegado de sua cidade (Jussara - GO). O documento foi produzido com o intuito de descrever a situação vivida pelo marido e também reforçar a necessidade da internação psiquiátrica.

A Sra. Joana, mãe de nove filhos menores, esposa do portador, cujo a conduz, está em séria dificuldade, devido a apresentação de debilidade mental, dizendo o marido que fora desde ocasião do último parto, mas, em verdade, esta esposa e mãe, deixa seus filhos e passa a perambular sem rumo e sem destino, esquecendo por completo as obrigações maternas e de esposa.

Não temos nenhum hospital nesta cidade que possa oferecer isolamento, e os médicos são clínicos ou cirúrgicos, e em especialidade do Hospital Psiquiátrico, não contamos com nenhum. E assim, reiteramos seja o cidadão atendido, para poder o mesmo cuidar de suas lavouras, porquanto não pode confiar e nem contar com a esposa, doente como apresenta (Ofício nº 79/79, Delegacia de Jussara - GO, Prontuário nº 1.432).

Pelas rasuras no prontuário, não soubemos por quanto tempo Joana permaneceu internada. Porém, uma anotação destaca que no ano de 1983, “os policiais trouxeram a paciente a pedido da família. Disseram que a paciente passou a noite toda dando banho em seu filhinho" (Prontuário $n^{\circ}$ 1.432). Nesse momento, diagnosticada com "alteração de comportamento", "auto e heteroagressividade", Joana, ao ser encaminhada para a enfermaria do Hospital Psiquiátrico Adauto Botelho, manifestou a sua recusa em permanecer no hospital psiquiátrico: “Eu não quero ficar no lugar das mulheres peladas, não!”.

Como se analisa, os discursos se entrecruzaram formando alianças que produziram uma verdade a respeito de Joana. Sendo o discurso um elemento estratégico das relações de poder e saber, conforme aponta Foucault (2006), nota-se que o discurso do marido que apresentou a demanda de internação relacionou e se sustentou no discurso do poder público. Já o poder psiquiátrico, que completou a tríade discursiva, tomou para si o encargo pelo asilamento e tratamento da paciente. 
Dessa forma, os discursos existentes a respeito de Joana apontaram para os arranjos entre os poderes na tentativa de afirmação do seu estado mental. Nessa perspectiva, o que estava em questão não era a loucura em si, pois já era evidente para o marido, o delegado e a psiquiatria que Joana apresentava comportamentos que não eram compatíveis com o que era considerado como normalidade - ora esquecia por completo as obrigações maternas e de esposa, ora passava a noite dando banho em seu filhinho. O que estava em jogo para esses poderes era a internação psiquiátrica enquanto estratégia necessária e mais adequada para a normalização dos comportamentos de Joana.

\section{Considerações finais}

Conforme analisado, padrões normativos atuaram decisivamente nas internações de mulheres no Hospital Psiquiátrico Adauto Botelho, influenciando, inclusive, muito além da própria visão médica e interpretação clínica do caso em questão. Assim, comportamentos não condizentes com a normalidade esperada para uma filha, esposa, mãe e dona de casa poderiam ser identificados como indícios de loucura; loucura que era construída de acordo com os comportamentos desviantes acusados pela própria sociedade e família, e aceitos como doença mental.

Cumpre destacar que o foco de nossa análise não foi questionar a existência ou não da doença mental nas internações, mas problematizar como os discursos científicos da psiquiatria ultrapassavam a própria ciência médica e se encontravam emaranhados nas práticas sociais. Dessa forma, mapeando os fragmentos de vida que emergiram nos prontuários psiquiátricos, evidenciamos que o saber médico psiquiátrico inseriu nas famílias e ajudou a desenhar o destino de muitas mulheres que foram internadas no hospital psiquiátrico.

Mulheres como Zélia, Helena, Naomi, Teresa, Divina, Adélia, Rosa, Luzia, Carmen, Joana e tantas outras que tiveram suas vidas atravessadas pelo poder psiquiátrico em suas alianças com a família e a sociedade. Múltiplos rostos, corpos rebeldes, indisciplinados e imorais, que se recusaram a ser o que era deles esperado e, por essa razão, foram submetidos aos discursos normativos (CARRION, 2011). Afinal de contas, vimos que o critério de normalidade estava muito além da perspectiva propriamente clínica.

Por fim, apresentamos aqui um dos modos de contar uma história; uma história que abre caminho para que outras possam ser escritas. Assim, as nossas problematizações ficam em aberto para que outros pesquisadores possam escrever sobre as vidas sem fama, sobre as 
“Eu não quero ficar no lugar das mulheres peladas, não!”: As causas das internações de mulheres no Hospital Psiquiátrico Adauto Botelho (Goiânia, Goiás). 229

existências-relâmpagos, como nos diz Foucault (1977), que se produziram no Hospital Psiquiátrico Adauto Botelho.

Dessas “vidas que são como se não tivessem existido, que só nos retornam pelo efeito de múltiplos acasos, eis as infâmias das quais eu quis, aqui, juntar alguns restos" (FOUCAULT, 1977: 210).

\section{Referências}

BIRMAN, Joel. A psiquiatria como discurso da moralidade. Rio de Janeiro: Edições Graal, 1978.

CARRION, Carla Torres Pereira. Desalinhados: uma história do Hospital Adauto Botelho e as memórias que ali habitam. Dissertação de Mestrado. Universidade Federal do Espírito Santo/UFES, Vitória, 2011.

COUTO, Cristina Carvalho de Medeiros. Eugenia, loucura e condição feminina. Cadernos de Pesquisa, São Paulo, n.90, p. 52-61, ago, 1994.

CUNHA, Maria Clementina Pereira da. Loucura, gênero feminino: as mulheres do Juquery na São Paulo do início do século XX. Revista Brasileira de História, v. 9, n. 18, p. 121144. 1989.

CUNHA, Maria Clementina Pereira da. O espelho do mundo: Juquery, a história de um asilo. Rio de Janeiro: Paz e Terra. 1986.

FOUCAULT, Michel. A Vida dos Homens Infames. In: Motta, M., B. (org.) Estratégia, podersaber/Michel Foucault. Rio de Janeiro: Forense Universitária, 1977.

FOUCAULT, Michel. Vigiar e punir: nascimento da prisão; tradução de Raquel Ramalhete. Petrópolis, Vozes, 1987.

FOUCAULT, Michel. O poder psiquiátrico: curso dado no Collège de France (1973-1974). São Paulo: Ed. Martins Fontes, 2006.

FOUCAULT, Michel. Os anormais. São Paulo: Ed. Martins Fontes, 2010.

GOFFMAN, Erving. Manicômios, prisões e conventos. São Paulo: Perspectiva. 1987.

MALUF, Marina; MOTT, Maria Lúcia. Recônditos do mundo feminino. In: Sevcenko, Nicolau (org.). História da vida privada no Brasil. República: da Belle Époque à Era do Rádio. São Paulo: Companhia das letras, 2006.

MOFFAT, Alfredo. Psicoterapia do oprimido: ideologia e técnica da psiquiatria popular. São Paulo: Cortez. 1980.

PAULA, Éder Mendes de. Os Sons do Silêncio: O louco e a loucura em Goiás. Dissertação de Mestrado. Universidade Federal de Goiás/UFG, Goiás, 2011.

PICCININI, Walmor J. Adauto Botelho: Notas Biográficas In: Psychiatry Brasil nº 02 Vol. 14 Fev. 2009.

SOUZA, Rildo Bento. Pobres, doentes e desvalidos: O asilo São Vicente de Paulo na Cidade de Goiás (1909-1935). Dissertação de Mestrado. Universidade Federal de Goiás/UFG, Goiás, 2010. 


\section{Fontes Documentais}

FOLHA DE GOYAZ. Tuberculosos no Adauto Botelho. 21 fev. 1961.

FOLHA DE GOYAZ. Proibidas as visitas no Hospital Psiquiátrico Adauto Botelho. 14 dez. 1958.

FOLHA DE GOYAZ. Inaugurado o Hospital Psiquiátrico. 04 abr. 1954.

JORNAL O POPULAR. Adauto Botelho fecha terça-feira. Goiânia, 29 de outubro de 1995.

JORNAL O POPULAR. Rejeição agrava males da doença mental. Goiânia, 02 de março de 1998.

PRONTUÁRIOS PSIQUIÁTRICOS - Hospital Psiquiátrico Adauto Botelho, pertencentes ao Arquivo da Secretaria Municipal de Saúde (Goiânia - GO): Paciente $\mathrm{n}^{\circ} 1$ - prontuário $\mathrm{n}^{\circ} 761$; paciente $\mathrm{n}^{\circ} 2$ - prontuário $\mathrm{n}^{\circ} 839$; paciente $\mathrm{n}^{\mathrm{o}} 3$ - prontuário $\mathrm{n}^{\mathrm{o}} 372$; paciente $\mathrm{n}^{\mathrm{o}}$ 4 - prontuário $\mathrm{n}^{\mathrm{o}} 1.104$; paciente $\mathrm{n}^{\circ} 5$ - prontuário $\mathrm{n}^{\mathrm{o}} 1.382$; paciente $\mathrm{n}^{\circ} 6$ - prontuário $\mathrm{n}^{\mathrm{o}}$ 1.723; paciente $\mathrm{n}^{\mathrm{o}} 7$ - prontuário $\mathrm{n}^{\circ} 1.457$; paciente $\mathrm{n}^{\circ} 8$ - prontuário $\mathrm{n}^{\circ} 1.432$.

Railda Aparecida Barbosa Barreto Mestre, Programa de Pós-graduação em Psicologia, Universidade Federal de Goiás (UFG).

E-mail: raildabbarreto@ hotmail.com

Tiago Cassoli Professor, Programa de Pós-graduação em Psicologia, Universidade Federal de Goiás (UFG). E-mail: cassolitiago2@gmail.com

\footnotetext{
${ }^{1}$ O Museu da Loucura em Barbacena (Minas Gerais) preserva partes da história do maior hospital psiquiátrico já construído no Brasil, o Hospital Colônia de Barbacena.

${ }^{2}$ Para garantir a privacidade quanto à identidade das pacientes, familiares e responsáveis, foram utilizados nomes fictícios.
} 